\title{
Progressive dementia associated with ataxia or obesity in patients with Tropheryma whipplei encephalitis
}

\author{
Florence Fenollar ${ }^{1}$, François Nicoli ${ }^{2,3}$, Claire Paquet ${ }^{4}$, Hubert Lepidi ${ }^{1}$, Patrick Cozzone ${ }^{3}$, Jean-Christophe Antoine ${ }^{5}$, \\ Jean Pouget $^{2}$ and Didier Raoult ${ }^{*}$
}

\begin{abstract}
Background: Tropheryma whipplei, the agent of Whipple's disease, causes localised infections in the absence of histological digestive involvement. Our objective is to describe T. whipplei encephalitis.

Methods: We first diagnosed a patient presenting dementia and obesity whose brain biopsy and cerebrospinal fluid specimens contained T. whipplei DNA and who responded dramatically to antibiotic treatment. We subsequently tested cerebrospinal fluid specimens and brain biopsies sent to our laboratory using T. whipplei PCR assays. PAS-staining and T. whipplei immunohistochemistry were also performed on brain biopsies. Analysis was conducted for 824 cerebrospinal fluid specimens and 16 brain biopsies.

Results: We diagnosed seven patients with T. whipplei encephalitis who demonstrated no digestive involvement. Detailed clinical histories were available for 5 of them. Regular PCR that targeted a monocopy sequence, PAS-staining and immunohistochemistry were negative; however, several highly sensitive and specific PCR assays targeting a repeated sequence were positive. Cognitive impairments and ataxia were the most common neurologic manifestations. Weight gain was paradoxically observed for 2 patients. The patients' responses to the antibiotic treatment were dramatic and included weight loss in the obese patients.
\end{abstract}

Conclusions: We describe a new clinical condition in patients with dementia and obesity or ataxia linked to T. whipplei that may be cured with antibiotics.

\section{Background}

Whipple's disease is a paradigm of the evolution of infectious disease knowledge [1]. The disease was first described in 1907 by Whipple [2], who based it on anatomopathological lesions identified in a patient at autopsy. For many years, it was considered to be a metabolic disorder; however, in 1952, a bacterial origin became suspected when antibiotic treatment proved effective [3]. The first molecular identification of the bacterium associated with Whipple's disease (Tropheryma whipplei), as well as the first culture, created a new field $[4,5]$. T. whipplei has been identified in the saliva and stool specimens of healthy people [1]. The

\footnotetext{
* Correspondence: didier.raoult@gmail.com

'Unité des rickettsies, URMITE CNRS-IRD UMR 6236, IFR 48, Faculté de

médecine, Université de la Méditerranée, Marseille, France

Full list of author information is available at the end of the article
}

well-known and classic form of Whipple's disease, which is characterised by periodic acid-Schiff (PAS)stained bacilli in infected small-bowel macrophages, represents only one rare clinical form of the infection that can be caused by $T$. whipplei. Indeed, the bacterium has also been involved in subacute or chronic infections without gut lesions, such as endocarditis, encephalitis, uveitis, adenopathy and pulmonary and osteoarticular infections [1,6-9]. The diagnosis and management are different for each of these infections $[1,9,10]$. Finally, acute T. whipplei infections, such as pneumonia [11,12], gastroenteritis [13] and transit bacteraemia [14], have recently been reported.

Neurologic forms are often the most serious manifestations of $T$. whipplei infection, particularly with respect to relapse treatment failure [15]. It has been noticed that relapses of classic Whipple's disease can be

\section{Biomed Central}

() 2011 Fenollar et al; licensee BioMed Central Ltd. This is an Open Access article distributed under the terms of the Creative Commons Attribution License (http://creativecommons.org/licenses/by/2.0), which permits unrestricted use, distribution, and reproduction in any medium, provided the original work is properly cited. 
exclusively cerebral, without any peripheral manifestations [1]. We recently diagnosed infection with $T$. whipplei in a patient who presented with progressive dementia and recent-onset obesity and responded dramatically to antibiotic treatment. This observation encouraged us to document additional cases of T. whipplei infections using brain biopsies and cerebrospinal fluid specimens.

\section{Methods}

Patients

\section{Patients from the study}

From January 2001 to June 2009, 824 cerebrospinal fluid specimens and 16 brain biopsies from patients without a previous diagnosis of Whipple's disease were analysed using PCR for T. whipplei in our laboratory in Marseille, France, which is a reference centre for T. whipplei diagnosis in our country. All samples were collected as part of routine clinical management, and they were sent to our laboratory for the detection of all microorganisms potentially responsible for encephalitis. Our diagnostic criteria for T. whipplei encephalitis required at least two positive PCR assays targeting 2 different sequences on 2 different cerebrospinal fluid specimens, performed as previously reported, or positive PCR assays on brain biopsies [16,17] and negative results PAS staining of gastric and small-bowel specimens, plus an absence of meningitis, myelitis, and other organ involvement. Our study is in compliance with the Helsinki declaration. The local ethics committee from IFR 48 (Marseille, France) approved this study. Written informed consent was obtained from the patient for the use of information in this case report and any accompanying images.

\section{Patients from the literature}

A MEDLINE (National Library of Medicine, Bethesda, MD) search of the literature from 1966 to April 2010 was performed. The following terms were used, both alone and combined: Tropheryma whipplei, Tropheryma whippelii, Whipple's disease, brain, cerebral, encephalitis and cerebrospinal fluid. References prior to 1966 were searched by cross referencing. Our initial analysis indicated considerable confusion in the literature regarding the specific diagnosis of $T$. whipplei encephalitis. We then applied rigorous criteria to classify the diagnosis as certain, possible or excluded. The diagnosis was considered certain only for patients with positive T. whipplei PCR, which allows the specific identification of the bacterium, and those with a negative PAS staining from gastric and small-bowel biopsies. Patients for whom digestive biopsies were not available were excluded from further analysis. Patients for whom the diagnosis was based solely on PAS staining of brain biopsies were also excluded; among 12 brain biopsies sent to our laboratory to confirm T. whipplei encephalitis (Table 1), all showed a nonspecific inflammatory process of the brain with numerous PAS-positive macrophages in the white matter, but specific immunohistochemistry yielded negative results. Patients who exhibited structures suggestive of bacterium under electron microscopy, along with positive PAS staining on brain biopsies, were classified as possible T. whipplei infection cases, as were patients with a diagnosis based exclusively on oculomasticatory myorhythmia. This rigorous strategy resulted in fewer patients with localised neurologic manifestations than have previously been reported [1].

\section{Methods}

\section{PCR assays, serologic studies and isolation procedures}

PCR assays were performed as previously reported [16-20]. Two hundred $\mu$ l cerebrospinal fluid specimens were submitted for DNA extraction using the QIAamp DNA MiniKit (Qiagen, Hilden, German) according to the manufacturer's recommendations. PCR mixes were prepared using a Fast-Start DNA Master SYBR Green kit (Roche, Mannheim, Germany) following the manufacturer's instructions. Quantitative PCR (qPCR) was performed in a LightCycler thermocycler (Roche biochemicals, Mannheim, Germany). For each assay, positive and negative controls were used. At intervals of 5 samples, negative controls (water, PCR mix and human samples) were evaluated. A tenfold dilution of a standard suspension of $10^{6} \mathrm{~T}$. whipplei strain MarseilleTwist was used as a positive control and for quantification, as previously reported [21]. The quality of DNA extraction from samples was estimated by PCR targeting a housekeeping gene coding $\beta$-actin. If a first PCR assay was positive, the result was systematically confirmed by a second PCR assay using a second set of primer pairs. In the event of discrepancies between the two PCR assays or incorrect controls, samples were submitted to new DNA extraction and/or new qPCR assays.

The PCR primers that we used have evolved with improved knowledge about T. whipplei. Between January 2001 and February 2004, all samples were tested using our regular qPCR, targeting a 489-bp fragment of the $16 \mathrm{~S}-23 \mathrm{~S}$ rRNA gene intergenic spacer using the primers tws3f (5'-CCGGTGACTTAACCTTTTTGGAGA) and tws4r (5'-TCCCGAGGCTTATCGCAGATTG), as previously reported [17]. If this assay was positive, a 650-bp fragment of the $r p o B$ gene using the primers TWRPOB. F (5'-TTTTTCCGGCGTGCGCTCAA) and TWRPOB.R (5'-TTTCTCCGAGGTTGCGGTGC) was performed [17]. For all of the assays, when an amplified product was detected, T. whipplei was systematically confirmed by sequencing, as previously reported [19]. Since October 2003, the availability of the T. whipplei genome has offered the option of using repeated sequences of T. whipplei for highly sensitive and specific PCR assays [16]. Subsequently, a PCR targeting repeated sequences 
Table 1 Summary of 14 brain biopsies from patients with encephalitis analysed in our laboratory using PAS staining, immunohistochemistry with polyclonal rabbit antibodies specifically directed against $T$. whipplei and specific PCR

\begin{tabular}{|c|c|c|c|c|c|}
\hline \multirow[b]{2}{*}{ Patients } & \multirow[b]{2}{*}{ Sex/Age } & \multirow[b]{2}{*}{ Country of origin } & \multicolumn{3}{|c|}{ Brain biopsies } \\
\hline & & & PAS staining & T. whipplei immunohistochemistry & T. whipplei PCR \\
\hline \multicolumn{6}{|c|}{ False-positive PAS staining associated with negative immunohistochemistry } \\
\hline \multicolumn{6}{|c|}{ Excluded diagnosis of $T$. whipplei encephalitis } \\
\hline *1 & $F / 67$ & Ireland & Positive & Negative & Negative \\
\hline *2 & $\mathrm{M} / 25$ & Canada & Positive & Negative & Negative \\
\hline *3 & $M / 42$ & France & Positive & Negative & Negative \\
\hline *4 & $M / 37$ & Belgium & Positive & Negative & Negative \\
\hline *5 & NA/NA & Japan & Positive & Negative & Negative \\
\hline *6 & $M / 34$ & France & Positive & Negative & Negative \\
\hline *7 & $M / 64$ & France & Positive & Negative & Negative \\
\hline *8 & M/66 & France & Positive & Negative & Negative \\
\hline \multicolumn{6}{|c|}{ Diagnosis of $T$. whipplei encephalitis not available due to lack of $P C R^{2}$} \\
\hline *9 & $\mathrm{M} / 73$ & Japan & Positive & Negative & $\mathrm{NA}^{1}$ \\
\hline *10 & $M / 14$ & USA & Positive & Negative & NA ${ }^{1}$ \\
\hline *11 & NA/NA & South-Africa & Positive & Negative & $\mathrm{NA}^{1}$ \\
\hline *12 & M/NA & Canada & Positive & Negative & NA ${ }^{1}$ \\
\hline \multicolumn{6}{|c|}{ False-negative PAS staining and immunohistochemistry } \\
\hline${ }^{* 2}$ Patient 1 in this study & $M / 39$ & France & Negative & Negative & Positive \\
\hline${ }^{* 2}$ Patient 5 in this study & $F / 33$ & France & Negative & Negative & Positive \\
\hline
\end{tabular}

of T. whipplei was developed that, when an amplified product was detected, confirmed the identification of $T$. whipplei by sequencing (between October 2003 and March 2004) or by using specific oligonucleotide Taqman* probes (since April 2004). From October 2003 to March 2004, T. whipplei qPCR targeting a 164-bp sequence of the bacterium incorporated the primer pairs 53.3F (5-AGAGAGATGGGGTGCAGGAC) and 53.3R (5'-AGCCTTTGCCAGACAGACAC) into the reaction mix. If this assay was positive, the result was confirmed by a second assay using a second set of primer pairs, 342F (5'-AGATGATGGATCTGCTTTCTTATCTG) and 492R (5'-AACCCTGTCCTGCACCCC), which targeted a different DNA sequence. Since April 2004, the reaction mix has included $T$. whipplei qPCR targeting a 155-bp sequence of the bacterium and incorporating the primer pair TW27F (5'-TGTTTTGTACTGCTTGTAACAGGATCT) and TW182R (5'-TCCTGCTCTATC CCTCCTATCATC) and a Taqman* probe (27F-182R, 6-FAM-AGAGATACATTTGTGTTAGTTGTTACATAMRA). If this assay was positive, the result was confirmed by a second assay using a second set of primer pairs TW13F (5'-TGAGTGATGGTAGTCTGAGAGA TATGT) and TW163R (5'-TCCATAACAAAGACA ACAACCAATC) and a Taqman* probe (13F-163R,
6-FAM-AGAAGAAGATGTTACGGGTTG-TAMRA) targeting a different 150-bp sequence [20-22]. Finally, all the cerebrospinal fluid specimens prior to October 2003 were retrospectively tested using PCR targeting repeated sequences, and the specimens sampled between October 2003 and February 2004 were tested using both regular and repeat PCR.

Serologic studies were performed as previously reported [23]. Cerebrospinal fluid specimens were cultivated using both cell-culture and cell-free culture media, as previously described [24,25].

\section{Brain magnetic resonance imaging and spectroscopy protocols}

Brain magnetic resonance examinations were performed on a $1.5 \mathrm{~T}$ Magnetom Vision Plus system (Siemens, Erlangen, Germany). The imaging protocol included one axial FLAIR sequence $(\mathrm{TR}=8000 \mathrm{~ms}$, $\mathrm{TI}=180 \mathrm{~ms}$, $\mathrm{TE}=110 \mathrm{~ms}$ ) and one axial T1-weighted sequence (TR $=644, \mathrm{~ms} \mathrm{TE}=15 \mathrm{~ms}$ ) performed before and after contrast agent administration $(0.2 \mathrm{ml} / \mathrm{kg}$ of GadoliniumDTPA, Guerbet, Paris, France). Magnetisation transfer imaging was performed using two axial proton-density weighted FLASH sequences $(\mathrm{TR}=500 \mathrm{~ms}$, TE $=4.7 \mathrm{~ms}$, 21 slices, thickness $=5 \mathrm{~mm}$, flip angle $=30^{\circ}$, without 
and with MT saturation: $1.5 \mathrm{kHz}$ off resonance, $500^{\circ}$, FOV $=240 \mathrm{~mm}$, matrix size $=256 \times 256)$. Diffusionweighted imaging was performed using a single-shot EPI sequence $\left(b=0,500,1000 \mathrm{~s} / \mathrm{mm}^{2}\right)$ applied in the $x, y$ and $\mathrm{z}$ directions (19 slices, thickness $=5 \mathrm{~mm}$, matrix size $\left.=128 \times 128, \mathrm{FOV}=256 \times 256 \mathrm{~mm}^{2}\right)$. Apparent diffusion coefficient (ADC) maps were reconstructed using this sequence. Single voxel proton magnetic resonance spectroscopy (SVS) included STEAM acquisition at an echo time of $20 \mathrm{~ms}$. TR was $1500 \mathrm{~ms}$. One voxel was centred on the medulla oblongata lesion, while the reference voxel was located on a contiguous area (the pons) that appeared normal on all MR sequences. The voxel volume was adapted to the size of the lesion. Several normal brain metabolites are detected using the STEAM 20 ms sequence: $\mathrm{N}$-acetylaspartate (NAA) is an amino acid that is present almost exclusively in neurons; reduced levels may correspond to neuronal death or injury. Myoinositol (MI) is a sugar that is only present in glia. It reduces when these cells experience specific damage and increases in cases of glial activation or proliferation (in glial tumours or reactive gliosis) [26]. Other molecules are detected under pathological conditions. Lactate and lipids or macromolecules may be detected when there is a local ischemia that eventually leads to necrosis (as with ischemic stroke and some tumours). Lactate may also be detected in relation to a macrophage infiltration. High lactate and lipid levels are also detected in cases of abscess. Other molecules such as succinate, acetate, alanine and other amino acids can be detected using in vivo magnetic resonance spectroscopy in cases of brain abscess, but only when the infectious lesion is cystic. Creatine/phosphocreatine $(\mathrm{tCr})$ is a ubiquitous metabolite involved in energy storage. It is a marker of overall cellular density. Choline (Cho) is mostly involved in cell membrane metabolism, and it is thus a membrane turnover marker. It increases whenever there is cellular proliferation (as with brain tumours), inflammation or membrane catabolism (as with multiple sclerosis).

\section{Statistical analysis}

Data were analysed using EpiInfo software, Version 3.4.1 (Centers for Disease Control and Prevention, Atlanta, GA, USA). $P<0.05$ was considered statistically significant.

\section{Results}

\section{Index patient}

A 39-year-old male (Patient 1) was hospitalised for cognitive impairment and choreiform movements. His medical history included a nearly 3 -week-long period of unexplained gastroenteritis 4 years earlier. Over a 3-year period, the patient developed hepatitis and obesity (a 25-kilogram weight gain) associated with hypercholesterolemia, hypertriglyceridemia and Type II diabetes. Hormonal evaluation showed peripheral hypoandrogenia with elevated levels of follicle-stimulating hormone. Brain magnetic resonance imaging (MRI) did not show any abnormalities. One year prior to hospitalisation, he developed dementia, dysarthria, and apathy, followed by involuntary and almost permanent choreiform movements of the left hemibody and abnormal buccofacial movements. No blood cell count abnormalities or C-reactive protein increases were observed. An increase in hepatic transaminases was identified. A lumbar puncture showed a high protein level $(4 \mathrm{~g} / \mathrm{l})$ with a normal glucose level. Examinations with brain computer tomography (CT) and brain MRI and spectroscopy were abnormal (Figure 1 and additional file 1, Figure S1). The MRI disclosed multiple unusual lesions corresponding to multiple brain lesions located in the medulla oblongata, hypothalamus, internal side of the right temporal lobe, fornix, lenticular nuclei and head of the caudate nuclei. These lesions showed high signal intensity on FLAIR images and low signal intensity on MT images, and they were slightly enhanced on T1-weighted images after gadolinium administration. Spectroscopy was characterised by a decrease in the NAA and MI peaks (consistent with neuronal and glial injury) and an increase in lipids and macromolecules, whereas lactate and other amino acids suggestive of an abscess were not detected. Finally, the absence of an increase in the choline-creatine ratio ruled out a demyelinating lesion or neoplasm. A brain biopsy was taken from the right striatum; it revealed astrocytic gliosis and vascular proliferation. No granulomas were observed. PAS staining and T. whipplei immunohistochemistry were negative. Regular PCR targeting the intertransgenic spacer (ITS) was negative for this brain biopsy; however, repeat PCR was positive for both the biopsy specimen and cerebrospinal fluids. One month after beginning specific treatment (doxycycline $200 \mathrm{mg}$, hydroxychloroquine $200 \mathrm{mg} 3$ times and trimethoprim-sulfamethoxazole $320+1,600 \mathrm{mg} 3$ times each per day), significant improvements were observed; however, cerebrospinal fluid showed persistent high protein levels, and repeat-PCR was still positive. After 2 months, the clinical examination was normal and, surprisingly, the patient had lost $17 \mathrm{~kg}$. One year after the start of the treatment, the patient's obesity had completely regressed, his hepatic tests were normal and he presented no evidence of diabetes; furthermore, brain MRI revealed that the majority of the lesions had disappeared. After 18 months of treatment, brain MRI and spectroscopy results were normal. The repeat PCR for cerebrospinal fluids was negative. The treatment was stopped. Fourteen months later, he experienced a clinical relapse, with weight gain (10 kilograms), the 


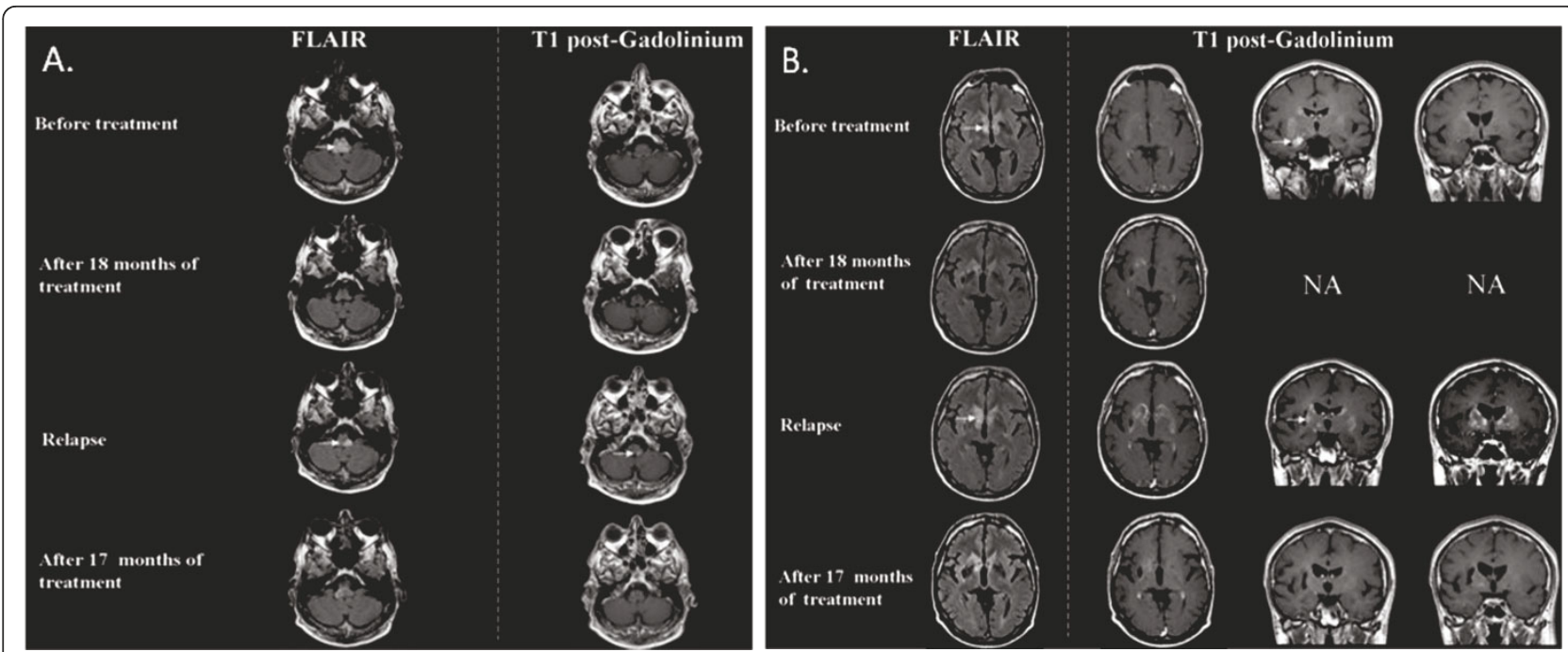

Figure 1 Figure 1a and 1b. Magnetic resonance examinations of Patient 1. MR examinations were performed on a 1.5 T Magnetom Vision Plus system (Siemens, Erlangen, Germany). The imaging protocol included one axial and coronal T2-weighted sequence and one axial T1weighted sequence, performed before and after contrast agent administration not at diagnosis but before treatment, after 18 months of treatment, at relapse, and after 17 months of a new treatment. A multimodal MRI of Patient 1 at the time of the diagnosis disclosed multiple brain lesions located in the medulla oblongata, the hypothalamus, the internal side of the right temporal lobe, the bilateral fornix, the lenticular nuclei and the head of caudate nuclei. These nonspecific, but unusual, lesions have a high signal intensity on FLAIR images and low signal intensity on MT images. They are slightly enhanced on T1-weighted images after gadolinium administration. Complete normalisation of the FLAIR abnormalities after 18 months of treatment were observed. A new lesion appeared in the left medulla oblongata during the relapse; it was enhanced after gadolinium injection. FLAIR abnormalities reappeared during the relapse, and lenticulocaudate gadolinium enhancement was also observed. A complete disappearance of the lesions after 17 months of treatment and the complete disappearance of gadolinium enhancement were also observed, in accordance with clinical improvement.

reappearance of diabetes, abnormal choreic movements, headache, difficulty concentrating and increased hepatic transaminases. Brain MRI and spectrometry showed signs of relapse, but T. whipplei repeat PCR for CSF was negative. A treatment based on doxycycline, hydroxychloroquine and sulfadiazine $(1,500 \mathrm{mg}$ four times per day) was started. All clinical abnormalities resolved, including obesity, similar to the patient's response to the first treatment. After 17 months of treatment, the patient's brain MRI was normal and spectroscopy was clearly improved. After 52 months, the treatment was stopped. Seventeen months after the completion of treatment, the patient showed no sequelae and felt well.

\section{Other patients}

The characteristics of 4 other patients with T. whipplei encephalitis (Patients 2, 3 and 4), seen by one of the authors (DR) in consultation, and 15 patients from the literature (8 with confirmed T. whipplei encephalitis and 7 with a possible diagnosis) are summarised in an additional file 2, Table S1 [27-43]. Seventy-four patients with Whipple's disease with neurologic manifestations and sufficient clinical information were also identified from the literature review [15,27,44-54]. Comparisons among the different groups are summarised in Tables 2 and 3.
T. whipplei encephalitis has two consistent findings: progressive cognitive impairment and the eventual onset of obesity or ataxia. For our 5 patients, the only diagnostic finding was a positive PCR of for cerebrospinal fluid and brain biopsies. This disease arises from the isolated involvement of T. whipplei localised to the central nervous system, which responded to antibiotic treatments. Among our patients and those in the literature, all 3 who did not receive antibiotics (because T. whipplei infection was diagnosed after post-mortem examination) died, compared with only 3 deaths among those who received antibiotics. This difference was statistically significant $(p=0.01)$. No specific brain MRI abnormalities were observed. Six out of 18 patients had a normal brain MRI.

\section{PCR assays, isolation procedure and serologic studies}

Among the 824 cerebrospinal fluid specimens, 7 (0.85\%) tested positive for T. whipplei DNA with PCR; 2 out of 16 brain biopsies were PCR positive, including a sample from one patient for whom cerebrospinal fluid was negative. Negative and positive controls were correct, including the amplification of the gene coding $\beta$-actin. All of our attempts to cultivate T. whipplei from the cerebrospinal fluid specimens of our 6 patients with T. whipplei encephalitis and positive PCR samples were 
Table 2 Features of patients with Whipple's disease [1], patients with Whipple's disease with neurological manifestations and patients with $T$. whipplei chronic encephalitis

\begin{tabular}{|c|c|c|c|c|c|}
\hline Feature & $\begin{array}{l}\text { Patients with } \\
\text { Whipple's } \\
\text { disease }\end{array}$ & $\begin{array}{l}\text { Patients with Whipple's disease } \\
\text { and neurological manifestations }\end{array}$ & $\begin{array}{l}\text { Patients with certain } T \text {. } \\
\text { whipplei encephalitis }\end{array}$ & $\begin{array}{l}\text { Patients with possible } \\
T \text {. whipplei encephalitis }\end{array}$ & $\begin{array}{l}\text { Patients with } \\
\text { certain } \\
\text { or possible } T \text {. } \\
\text { whipplei } \\
\text { encephalitis }\end{array}$ \\
\hline & \multicolumn{5}{|c|}{ No./total no. (\%) } \\
\hline Male sex & $770 / 886(87)$ & $57 / 74(77)$ & $8 / 13(61.5)$ & 4/7 (57) & $12 / 20(60)$ \\
\hline Age & NA & $50 \pm 13$ & $50 \pm 13$ & $52 \pm 12$ & $51 \pm 12$ \\
\hline $\begin{array}{l}\text { Arthralgia } \\
\text { or arthritis }\end{array}$ & 244/335 (73) & 49/74 (66) & 1/11 (9) & $3 / 7(43)$ & $4 / 18(22)$ \\
\hline $\begin{array}{l}\text { Chronic } \\
\text { diarrhoea }\end{array}$ & $272 / 335(81)$ & $30 / 74(40.5)$ & $0 / 12$ & $0 / 6$ & $0 / 18$ \\
\hline $\begin{array}{l}\text { Weight } \\
\text { loss }\end{array}$ & $223 / 240(93)$ & $35 / 57(47)$ & $1 / 11(9)$ & $0 / 6$ & $1 / 17(6)$ \\
\hline
\end{tabular}

NA: Not available

Table 3 Clinical features* of 74 patients with Whipple's disease (i.e., patients with histological digestive involvement characterised by positive PAS staining) with neurologic manifestations and those with certain (13) and possible (7) T. whipplei chronic encephalitis without digestive lesions

\begin{tabular}{|c|c|c|c|c|}
\hline $\begin{array}{l}\text { Neurologic } \\
\text { manifestations }\end{array}$ & $\begin{array}{l}\text { Whipple's disease with neurologic } \\
\text { manifestations }\end{array}$ & $\begin{array}{l}\text { Certain } T . \text { whipplei } \\
\text { encephalitis }\end{array}$ & $\begin{array}{l}\text { Possible } T \text {. whipplei } \\
\text { encephalitis }\end{array}$ & $\begin{array}{l}\text { Certain and } \\
\text { possible } \\
T . \text { whipplei } \\
\text { encephalitis }\end{array}$ \\
\hline Number of patients & 74 & 13 & 7 & 20 \\
\hline Cognitive impairment & $53(72 \%)$ & $9(69 \%)$ & $7(100 \%)$ & $16(80 \%)$ \\
\hline Ataxia & $12(16 \%)$ & $9\left(69 \% ; p<10^{-3}\right)$ & $4(57 \% ; p=0.02)$ & $13\left(65 \% ; p<10^{-3}\right)$ \\
\hline $\begin{array}{l}\text { Supranuclear } \\
\text { ophthalmoplegia }\end{array}$ & $29(39 \%)$ & $5(38 \%)$ & $4(57 \%)$ & $9(45 \%)$ \\
\hline $\begin{array}{l}\text { Hypothalamic } \\
\text { manifestations }\end{array}$ & $24(32 \%)$ & $4(31 \%)$ & $2(29 \%)$ & $6(30 \%)$ \\
\hline Dysarthria & $9(12 \%)$ & $4(31 \%)$ & $3(43 \%)$ & $7(35 \% ; p=0.03)$ \\
\hline Cerebellar forms & $4(5.5 \%)$ & $3(23 \% ; p=0.06)$ & $3(43 \% ; p=0.03)$ & $\begin{array}{l}6(26 \% \\
p=0.005)\end{array}$ \\
\hline Myorhythmia & $10(13.5 \%)$ & $4(31 \%)$ & $3(43 \%)$ & $\begin{array}{l}7(35 \% \\
p=0.045)\end{array}$ \\
\hline $\begin{array}{l}\text { Oculomasticatory } \\
\text { myorhythmia }\end{array}$ & $7(5.5 \%)$ & $2(17 \%)$ & $2(29 \%)$ & $4(20 \%)$ \\
\hline $\begin{array}{l}\text { Upper motor neuron } \\
\text { disorder }\end{array}$ & $11(15 \%)$ & $4(31 \%)$ & $3(43 \%)$ & $7(35 \%)$ \\
\hline $\begin{array}{l}\text { Decreasing level of } \\
\text { consciousness }\end{array}$ & $25(35 \%)$ & $2(15 \%)$ & $6(75 \% ; p=0.01)$ & $8(40 \%)$ \\
\hline Myoclonus & $29(39 \%)$ & $3(23 \%)$ & $1(14 \%)$ & $4(20 \%)$ \\
\hline Depression & $11(15 \%)$ & $3(23 \%)$ & $1(14 \%)$ & $3(15 \%)$ \\
\hline Personality changes & $22(30 \%)$ & $2(15 \%)$ & $2(29 \%)$ & $4(20 \%)$ \\
\hline Headache & $10(13.5 \%)$ & $1(8 \%)$ & $2(29 \%)$ & $3(15 \%)$ \\
\hline Apathy & $15(20 \%)$ & $1(8 \%)$ & $1(14 \%)$ & $2(10 \%)$ \\
\hline Muscle weakness & $14(19 \%)$ & $2(15 \%)$ & $2(29 \%)$ & $4(20 \%)$ \\
\hline Seizures & $13(18 \%)$ & $3(23 \%)$ & $1(14 \%)$ & $4(20 \%)$ \\
\hline Nystagmus & $11(15 \%)$ & $3(23 \%)$ & $1(14 \%)$ & $4(20 \%)$ \\
\hline $\begin{array}{l}\text { Extrapyramidal movement } \\
\text { disorder }\end{array}$ & $8(11 \%)$ & $2(17 \%)$ & $2(29 \%)$ & $4(20 \%)$ \\
\hline
\end{tabular}

Significant $p$ values are noted in bold.

* Neurological signs were defined as follows: "Decreasing level of consciousness" included somnolence, lethargy, and coma. "Cognitive impairment" included abnormalities of orientation, memory, or reasoning. "Hypothalamic manifestations" included polydipsia, hyperphagia, sexual impotence, changes in the sleepwake cycle and insomnia, but not isolated somnolence. Oculomasticatory myorhythmia was defined as pendular vergence oscillations of the eyes that were synchronous with masticatory myorhythmia. Both were classified as myorhythmia. "Myoclonus", which is nonrhythmic, was distinguished from myorhythmia. "Cerebellar forms" were considered when a patient presented dysarthria and ataxia. 
unsuccessful; in contrast, we established 9 strains of T. whipplei from the cerebrospinal fluid specimens of patients with classic Whipple's disease with associated neurologic manifestations (6/8), asymptomatic neurologic involvement $(2 / 4)$, or neurologic relapse (1/3) (published and unpublished data) [1]. This difference was statistically significant $(p<0.017)$. We hypothesised that this difference might be linked to a lower amount of bacteria in the cerebrospinal fluid specimens of patients with T. whipplei encephalitis. Serum sample serologic tests were available from 5 patients with $T$. whipplei encephalitis. Of these, 2 showed no reaction and 3 showed low-level but specific responses to the deglycosylated proteins of $T$. whipplei, as has been observed in patients with classic Whipple's disease [23].

\section{Discussion}

We describe a clinical phenomenon of patients with T. whipplei who present with isolated brain involvement and respond dramatically to antibiotic treatment. Their condition was poor and worsening at the time of the diagnosis. As in the review of the literature, the antibiotics address the progressive cognitive impairment. In our index patient, antibiotic therapy not only improved his clinical status but also caused a reversal of obesity, both at the time of the initial diagnosis and upon relapse. These observations are reminiscent of those described in 1952 after the first successful use of an antibiotic (chloramphenicol) to treat Whipple's disease, which suggested that the disease had a bacterial origin [3].

The amount of T. whipplei DNA in the cerebrospinal fluid specimens of the patients described in our series was low, as demonstrated by our quantitative PCR assays; however, we are confident that these results are accurate, because we performed 2 PCR tests on 2 different samples to confirm the diagnosis. Our attempts to isolate a strain from the cerebrospinal fluid specimens failed, although we were able to isolate strains from other cerebrospinal fluids from patients with classic Whipple's disease with a good percentage of success (60\%). Even in the 2 brain biopsies from our patients, only very low copies of $T$. whipplei DNA were detected. Moreover, these 2 brain biopsies were PAS negative and T. whipplei immunohistochemistry negative. It is also important to note that these data are different from those of patients in the literature with positive PAS staining of brain biopsies. Indeed, there is a link between the clinical picture of our patients and T. whip$p l e i$, but we were unable to identify histological findings compatible with described T. whipplei-associated diseases. However, it has also recently been reported that T. whipplei DNA is highly frequent in the skin biopsies of patients with classic Whipple's disease, whereas PAS staining is significantly less sensitive in the same group [55]. Furthermore, these bacteria are alive, as a positive culture from a skin specimen has been obtained. Overall, these data show that PAS staining, which was long considered the gold standard for diagnosing T. whipplei infection, is frequently negative, despite the presence of T. whipplei infection.

Overall, only 4 (18\%) out of 18 patients reviewed here reported a history of arthralgia, despite its description as a cardinal symptom of classic Whipple's disease (73\%) [1]. Our study patients reported no chronic diarrhoea, whereas it is observed in $81 \%$ of patients with classical Whipple's disease and $40.5 \%$ of patients with a neurologic presentation of Whipple's disease [1]. It is interesting to note that 3 of our 5 patients reported a history of unexplained acute diarrhoea prior to the onset of neurologic symptoms, which may correspond to primary infection with $T$. whipplei, as described previously in young children [13]. Weight loss was observed for none of our patients and only one from the literature versus 93\% of patients with classic Whipple's disease and 47\% of patients with a neurologic presentation of Whipple's disease [1]. Even more interesting, 2 of our 5 patients developed obesity during the primary illness or during the relapse. Several viruses have been reported to contribute to weight gain in animals [56]. In humans, one adenovirus has been also identified as a possible contributor to weight gain [56]. The most likely mechanisms are a central effect on appetite and energy expenditure associated with hypothalamic infiltration by the pathogen. This clinical picture may be a particular form caused by $T$. whipplei. It appears that this clinical entity resembles a localised cerebral relapse of classic Whipple's disease when bacterial multiplication is relatively controlled. Another interesting observation is the deficient humoural responses against $T$. whipplei in patients with T. whipplei encephalitis, as have been described in patients with Whipple's disease compared with asymptomatic carriers [23].

This clinical entity seems rare, as only $0.85 \%$ of cerebrospinal fluid specimens of patients with unexplained dementia or encephalitis tested in our laboratory were positive. However, our technique may lack sensitivity in some cases, as the repeat PCR assays were unable to detect T. whipplei when brain MRI-spectroscopy showed lesions compatible with reactive disease at the time of clinical relapse. Furthermore, the lack of information about antibiotic treatment status prior to cerebrospinal fluid sampling for most of the patients must also lead us to regard this prevalence cautiously, as antibiotic use might explain some negative PCR results. As seen in our patients, PAS staining of brain biopsy specimens with $T$. whipplei also lacks sensitivity. Furthermore, this tests lacks specificity, as perivascular aggregates of 
foamy PAS-positive macrophages in a reactive gliosis setting can be seen in other macrophage-rich cerebral disorders, such as demyelinating diseases, cerebral infarction, and a host of infectious diseases [57]. The results of PAS-staining of brain biopsy specimens can neither confirm nor exclude the diagnosis of $T$. whipplei encephalitis. The development of cognitive impairments associated with ataxia or obesity should point the clinician to a diagnosis of $T$. whipplei encephalitis.

PCR testing of cerebrospinal fluid specimens for $T$. whipplei in neurological patients is clinically reasonable, as the disease is fatal without specific treatment. As is the case for all diagnoses performed using PCR, caution is necessary, and a rigorous strategy should be applied when performing and interpreting the analyses due to the risk of false-positive results [58]. A carefully checked positive PCR in cerebrospinal fluid specimens is sufficient for diagnosis. It is important to remember the patient for whom a Whipple's disease diagnosis was ruled out by negative PAS staining, despite positive PCR, and then finally confirmed using both techniques at the patient's autopsy [59].

Another question concerns the management of this presentation. Advances in knowledge, with in vitro tests and full genome sequencing of T. whipplei, have shown that the usual long-term treatment based on trimethoprim-sulfamethoxazole is a sulfonamide monotherapy and that an alternative may be doxycycline and hydroxychloroquine, an alkalinising agent $[1,60,61]$. However, it is noteworthy to remember that trimethoprim-sulfamethoxazole has replaced cyclines, which had the reputation of not crossing the blood-brain barrier in adequate amounts, an issue that has not yet been confirmed for doxycycline [10]. That is why we first used a combination of doxycycline, hydroxychloroquine and trimethoprim-sulfamethoxazole to manage T. whipplei encephalitis. However, recent evidence suggests that sulfadiazine is preferable; its efficacy is comparable to that of the sulfomethoxazole, but a higher dose of sulfadiazine can be used to improve its ability to cross the blood-brain barrier [10]. Antibiotics had a quick effect. However, 3 of our 5 patients presented with clinical relapse despite at least 18 months of therapy. When the treatment was reintroduced, a quick effect was again observed. As for classic Whipple's disease, the optimal treatment for T. whipplei encephalitis has not yet been determined [10]. Overall, the data emphasise the need for long-term treatment and lifelong follow-up.

\section{Conclusion}

We describe a clinical entity that presents with unexplained progressive dementia, generally associated with ataxia or recent obesity, and responds dramatically to antibiotics. We suspect that many more cases may be observed, as 3 of the recorded patients were hospitalised in Marseille, where the study was performed.

\section{Additional material} Additional File 1: Figure S1. Magnetic resonance spectroscopy results*
of patient 1.

Additional file 2: Table S1. Summary of 20 patients with T. whipplei chronic encephalitis

\section{Acknowledgements}

We thank Dr Christopher D. Paddock for reviewing the manuscript and Patrick Viout for technical help.

\section{Author details}

'Unité des rickettsies, URMITE CNRS-IRD UMR 6236, IFR 48, Faculté de médecine, Université de la Méditerranée, Marseille, France. ${ }^{2}$ Service de Neurologie, Hôpital de La Timone, Marseille, France. ${ }^{3}$ Centre de Résonance Magnétique Biologique et Médicale and Centre d'Exploration Métabolique par Résonance Magnétique, UMR CNRS 6612, Faculté de Médecine, Université de la Méditerranée, and Hôpital de La Timone, Marseille, France. ${ }^{4}$ Memory Center, Department of Pathology, Lariboisière Fernand Widal Hospital University of Paris 7 and INSERM UMRS 839, France. ${ }^{5}$ Service de Neurologie, CHU de Saint-Etienne, France.

\section{Authors' contributions}

DR designed the study and analysed the data. FF, FN, CP, JCA, PC, HL and JP collected and analysed the data. FF and DR wrote the manuscript. All authors read and approved the final manuscript.

\section{Competing interests}

The authors declare that they have no competing interests.

Received: 3 May 2010 Accepted: 15 June 2011 Published: 15 June 2011

\section{References}

1. Fenollar F, Puéchal X, Raoult D: Whipple's disease. New Engl J Med 2007, 356:55-66.

2. Whipple $\mathrm{GH}$ : A hitherto undescribed disease characterised anatomically by deposits of fat and fatty acids in the intestinal and mesenteric lymphatic tissues. Bull Johns Hopkins Hosp 1907, 18:382-391.

3. Paulley JW: A case of Whipple's disease (intestinal lipodystrophy). Gastroenterology 1952, 22:128-133.

4. Wilson KH, Blitchington R, Frothingham R, Wilson JA: Phylogeny of the Whipple's disease-associated bacterium. Lancet 1991, 338:474-475.

5. Raoult D, Birg M, La Scola B, Fournier P, Enea M, Lepidi H, et al: Cultivation of the bacillus of Whipple's disease. N Engl J Med 2000, 342:620-625.

6. Gubler JG, Kuster M, Dutly F, Bannwart F, Krause M, Vögelin HP, et al: Whipple endocarditis without overt gastrointestinal disease: Report of four cases. Ann Intern Med 1999, 131:112-116.

7. Rickman LS, Freeman WR, Green WR, Feldman ST, Sullivan J, Russack V, et al: Uveitis caused by Tropheryma whippelii (Whipple's bacillus). N Engl J Med 1995, 332:363-366.

8. Drancourt M, Fenollar F, Denis D, Raoult D: Postoperative panophthalmitis caused by Whipple disease. Emerg Infect Dis 2009, 15:825-827.

9. Lagier JC, Lepidi H, Raoult D, Fenollar F: Clinical presentation of 142 patients with systemic Tropheryma whipplei infections diagnosed or confirmed in a reference center. Medicine (Baltimore) 2010, 89:337-345.

10. Fenollar F, Raoult D: How should classic Whipple's disease be managed? Nat Rev Gastroenterol Hepatol 2010, 7:246-248.

11. Harris JK, De Groote MA, Sagel SD, Zemanick ET, Kapsner R, Penvari C, et al: Molecular identification of bacteria in bronchoalveolar lavage fluid from children with cystic fibrosis. Proc Natl Acad Sci USA 2007, 104:20529-20533.

12. Bousbia S, Papazian L, Auffray JP, Fenollar F, Martin C, Li W, et al: Molecular analysis of bronchoalveolar lavage in patients with pneumonia reveals the presence of Tropheryma whipplei. Emerg Infect Dis 2010, 16:258-263. 
13. Raoult D, Fenollar F, Rolain JM, Minodier P, Bosdure E, Li W, et al: Tropheryma whipplei is commonly associated to gastroenteritis in young children. Emerg Infect Dis 2010, 16:776-782.

14. Fenollar F, Mediannikov O, Socolovschi C, Bassene H, Diatta G, Richet H, et al: Tropheryma whipplei bacteremia during fever in rural West Africa. Clin Infect Dis 2010, 51:515-521.

15. Gerard A, Sarrot-Reynauld F, Liozon E, Cathébras P, Besson G, Robin C, et al: Neurologic presentation of Whipple disease: report of 12 cases and review of the literature. Medicine (Baltimore) 2002, 81:443-457.

16. Fenollar F, Fournier PE, Robert C, Raoult D: Use of genome selected repeated sequences increases the sensitivity of PCR detection of Tropheryma whipplei. J Clin Microbiol 2004, 42:401-403.

17. Fenollar F, Fournier PE, Raoult D, Gerolami R, Lepidi H, Poyart C: Quantitative detection of Tropheryma whipplei DNA by real-time PCR. $J$ Clin Microbiol 2002, 40:1119-1120.

18. Fenollar F, Laouira S, Lepidi H, Rolain J, Raoult D: Value of Tropheryma whipplei quantitative PCR assay for the diagnosis of Whipple's disease usefulness of saliva and stool specimens for first line screening. Clin Infect Dis 2008, 47:659-667.

19. La Scola B, Fenollar F, Fournier PE, Altwegg M, Mallet MN, Raoult D: Description of Tropheryma whipplei gen. nov., sp. nov., the Whipple's disease bacillus. Int J Syst Evol Microbiol 2001, 51:1471-1479.

20. Rolain JM, Fenollar F, Raoult D: False positive PCR detection of Tropheryma whipplei in the saliva of healthy people. BMC Microbio/ 2007, 7:48.

21. Fenollar F, Trani M, Davoust B, Salle B, Birg ML, Rolain JM, et al: Carriage of Tropheryma whipplei in stools of sewer workers and human controls, but not in monkeys and apes. J Infect Dis 2008, 197:880-887.

22. Raoult D, Fenollar F, Birg ML: Culture of Tropheryma whipplei from the stool of a patient with Whipple's disease. N Engl J Med 2006, 355:1503-1505.

23. Fenollar F, Amphoux B, Raoult D: A paradoxical Tropheryma whipplei western blot differentiates patients with Whipple's disease from asymptomatic carriers. Clin Infect Dis 2009, 49:717-723.

24. Fenollar F, Birg ML, Gauduchon V, Raoult D: Culture of Tropheryma whipplei from human samples: A 3-year experience (1999 to 2002). J Clin Microbiol 2004, 41:3816-3822.

25. Renesto P, Crapoulet N, Ogata H, La Scola B, Vestris G, Claverie JM, et al: Genome-based design of a cell-free culture medium for Tropheryma whipplei. Lancet 2003, 362:447-449.

26. Galanaud D, Nicoli F, Le Fur Y, Guye M, Ranjeva JP, Confort-Gouny S, et al: Multimodal magnetic resonance imaging of the central nervous system. Biochimie 2003, 85:905-914.

27. Louis ED, Lynch T, Kaufmann P, Fahn S, Odel J: Diagnostic guidelines in central nervous system Whipple's disease. Ann Neurol 1996, 40:561-568.

28. Coria F, Cuadrado N, Velasco C, Jiménez Carmena JJ, Jiménez MI, Mena FJ et al: Whipple's disease with isolated central nervous system symtomatology diagnosed by molecular identification of Tropheryma whippelii in peripheral blood. Neurologia 2000, 15:173-176.

29. von Herbay A, Ditton HJ, Schuhmacher F, Maiwald M: Whipple's disease: staging and monitoring by cytology and polymerase chain reaction analysis of cerebral fluid. Gastroenterology 1997, 113:434-441.

30. Rossi T, Haghighipour M, Haghighi M, Paolini S, Scarpino O: Cerebral Whipple's disease as a cause of reversible dementia. Clin Neurol Neurosurg 2005, 107:258-261.

31. Averbuch-Heller L, Paulson G, Daroff R, Leight J: Whipple's disease mimicking progressive supranuclear palsy: the diagnostic value of eye movement recording. I Neurol Neurosurg Psychiatry 1999, 66:532-535.

32. Halperin J, Landis D, Kleinman G: Whipple disease of the nervous system. Neurology 1982, 32:612-617.

33. Brown A, Lane J, Murayama S, Vollmer D: Whipple's disease presenting with isolated neurological symptoms. J Neurosurg 1990, 73:623-627.

34. Nelson JW, White ML, Zhang Y, Moritani T: Proton magnetic resonance spectroscopy and diffusion-weighted imaging of central nervous system Whipple disease. J Comput Assist Tomogr 2005, 29:320-322.

35. Henning S, Tings T, Schmidt H, Tergau F, Wolf S, Scholz K, et al: A case of cerebral Whipple's disease initially presenting with isolated focal myoclonus. Eur J Neurol 2006, 13:659-661.

36. Panegyres PK, Edis R, Beaman M, Fallon M: Primary Whipple's disease of the brain: characterisation of the clinical syndrome and molecular diagnosis. QJM 2006, 99:609-623.

37. Lee AG: Whipple disease with supranuclear ophtalmoplegia diagnosed by polymerase chain reaction of cerebrospinal fluid. $J$ Neuroophtamol 2002, 22:18-21.
38. Romanul F, Radvany J, Rosales R: Whipple's disease confined to the brain: a case studied clinically and pathologically. J Neurol Neurosurg Psychiatry 1977, 40:901-909.

39. Wroe S, Pires M, Harding B, Youl B, Shorvon S: Whipple's disease confined to the CNS presenting with multiple intracerebral mass lesions. J Neurol Neurosurg Psychiatry 1991, 54:989-992.

40. Posada IJ, Ferreiro-Sieiro A, Lopez-Valdes E, Cabello A, Bermejo-Pareja F: Whipple's disease confined to the brain. A clinical case with pathological confirmation at necropsy. Rev Neurol 2004, 38:196-198.

41. Adams M, Rhyner P, Day J, DeArmond S, Smuckler E: Whipple's disease confined to the central nervous system. Ann Neurol 1987, 21:104-108.

42. Schwartz M, Selhorst J, Ochs A, Beck R, Campbell W, Harris J, et al: Oculomasticatory myorhythmia: a unique movement disorder occurring in Whipple's disease. Ann Neurol 1986, 20:677-683.

43. Peters G, du Plessis DG, Humphrey PR: Cerebral Whipple's disease with a stroke-like presentation and cerebrovascular pathology. J Neurol Neurosurg Psychiatry 2002, 73:336-339.

44. Dobbins WO III: Whipple's disease. Thomas Books Springfield, IL; 1987.

45. Bernachon E, Laxenaire N, Le Baleur Y, Miquel J, Bernachon-Agache F, Gillot JM: La curiosité est un joli défaut. Rev Med Int 2003, 25:157-159.

46. Codden T, Lenaerts A, Chaikh A, Henry JP: Whipple disease revealed by weight loss and neurologic signs. Gastroenterol Clin Biol 2003, 27:834-836.

47. Dhote R, Mir O, Moulin V, Ropert S, Permal S, Scavennec R, et al: Un glissement trop fébrile. Rev Med Int 2003, 24(Suppl 2):259-260.

48. Levy S, Degott C, Redondo A, Benhamou JP, Bernuau J: Acute intracranial hypertension and anicteric cholestasis revealing Whipple's disease without digestive involvement. Gastroenterol Clin Biol 2001, 25:100-102.

49. Matthews BR, Jones LK, Saad DA, Aksamit AJ, Josephs KA: Cerebellar ataxia and central nervous system Whipple disease. Arch Neurol 2005, 62:618-620.

50. Reyes MC, Cordero FC, Torronteras SR, Reina Campos FR, Marquez Galan JL, Sanchez AM: Whipple's disease: report of cases diagnosed in our hospital. Rev Esp Enferm Dig 2003, 95:149-8.

51. Pruss H, Katchanov J, Zschenderlein R, Loddenkemper C, Schneider T, Moos $V$ : A patient with cerebral Whipple's disease with gastric involvement but no gastrointestinal symptoms - a consequence of local protective immunity? J Neurol Neurosurg Psychiatry 2007, 78:896-898.

52. Maia LF, Marta M, Lopes V, Rocha N, Lopes C, Martins-da-Silva A, et al: Hypersomnia in Whipple disease: case report. Arq Neuropsiquiatr 2006, 64:865-868.

53. Magherini A, Pentore R, Grandi M, Leone ME, Nichelli PF: Progressive supranuclear gaze palsy without parkinsonism: a case of neuro-Whipple. Parkinsonism Relat Disord 2007, 13:449-452.

54. Famularo G, Minisola G, De SC: A patient with cerebral Whipple's disease and a stroke-like syndrome. Scand J Gastroenterol 2005, 40:607-609.

55. Angelakis E, Fenollar F, Lepidi H, Birg ML, Raoult D: Tropheryma whipplei in the skin of patients with classic Whipple's disease. J Infect 2010, 61:266-269.

56. Vasilakopoulou A, le Roux CW: Could a virus contribute to weight gain? Int J Obes (Lond) 2007, 31:1350-1356.

57. Marth T, Raoult D: Whipple's disease. Lancet 2003, 361:239-246.

58. Goyo D, Camacho A, Gomez C, de Las Heras RS, Otero JR, Chaves F: Falsepositive PCR detection of Tropheryma whipplei in cerebrospinal fluid and biopsy samples from a child with chronic lymphocytic meningitis. J Clin Microbiol 2009, 47:3783-3784.

59. Müller SA, Vogt P, Altwegg M, Seebach JD: Deadly carousel or difficult interpretation of new diagnostic tools for Whipple's disease: case report and review of the literature. Infection 2005, 33:39-42.

60. Ghigo E, Capo C, Aurouze M, Tung CH, Gorvel JP, Raoult D, et al: Survival of Tropheryma whipplei, the agent of Whipple's disease, requires phagosome acidification. Infect Immun 2002, 70:1501-1506.

61. Lagier JC, Fenollar F, Lepidi H, Raoult D: Failure and relapse after treatment with Trimethoprim-Sulfamethoxazole in classic Whipple's disease. J Antimicrob Chemother 2010, 65:2005-2012.

\section{Pre-publication history}

The pre-publication history for this paper can be accessed here: http://www.biomedcentral.com/1471-2334/11/171/prepub

\section{doi:10.1186/1471-2334-11-171}

Cite this article as: Fenollar et al:: Progressive dementia associated with ataxia or obesity in patients with Tropheryma whipplei encephalitis. BMC Infectious Diseases 2011 11:171. 